\title{
Planarians: an In Vivo Model for Regenerative Medicine
}

\author{
Ali Karami, Hamid Tebyanian, Vahabodin Goodarzi, Sajad Shiri \\ Applied Biotechnology Research Center, Baqiyatallah University of Medical Sciences, Tehran, Iran
}

The emergence of regenerative medicine has raised the hope of treating an extraordinary range of disease and serious injuries. Understanding the processes of cell proliferation, differentiation and pattern formation in regenerative organisms could help find ways to enhance the poor regenerative abilities shown by many other animals, including humans. Recently, planarians have emerged as an attractive model in which to study regeneration. These animals are considering as in vivo plate, during which we can study the behavior and characristics of stem cells in their own niche. A variety of characteristic such as: simplicity, easy to manipulate experimentally, the existence of more than 100 years of literature, makes these animals an extraordinary model for regenerative medicine researches. Among planarians free-living freshwater hermaphrodite Schmidtea mediterranea has emerged as a suitable model system because it displays robust regenerative properties and, unlike most other planarians, it is a stable diploid with a genome size of about $4.8 \times 10^{8}$ base pairs, nearly half that of other common planarians. Planarian regeneration involves two highly flexible systems: pluripotent neoblasts that can generate any new cell type and muscle cells that provide positional instructions for the regeneration of anybody region. neoblasts represent roughly $25 \sim 30$ percent of all planarian cells and are scattered broadly through the parenchyma, being absent only from the animal head tips and the pharynx. Two models for neoblast specification have been proposed; the naive model posits that all neoblasts are stem cells with the same potential and are a largely homogeneous population.

Keywords: Neoblast, Regenerative medicine, Blastema, Differentiation, Schmidtea mediterranea

\section{What are neoblasts?}

Having an almost unlimited capacity to regenerate tissues lost to age and injury, planarians have long fascinated naturalists. In the Western hemisphere alone, their documented history spans more than 200 years. Planarians were described in the early 19th century as being immortal under the edge of the knife (1). Among planarians,

\footnotetext{
Accepted for publication July 22, 2015, Published online November 30, 2015 Correspondence to Hamid Tebyanian

Applied Biotechnology Research Center, Baqiyatallah University of Medical Sciences, Tehran 1435944711, Iran

Tel: +989198045743, Fax: +982-21-886-22356

E-mail: Tebyan.hamid@yahoo.com

(c) This is an open-access article distributed under the terms of the Creative Commons Attribution Non-Commercial License (http://creativecommons.org/ licenses/by-nc/4.0/), which permits unrestricted non-commercial use, distribution, and reproduction in any medium, provided the original work is properly cited.
}

free-living freshwater hermaphrodite Schmidtea mediterranea has emerged as a suitable model system because it displays robust regenerative properties and, unlike most other planarians, it is a stable diploid $(2 \mathrm{n}=8)$ with a genome size of about $4.8 \times 10^{8}$ basepairs (nearly half that of other common planarians). Moreover, a Robertsonian translocation (that is, the fusion of a whole arm of chromosome 1 to chromosome 3) has produced an exclusively asexual biotype. Both sexual and asexual forms have proven easy to rear in the laboratory (2). The capacity of regeneration in planarians is mediated by a proliferative cell population that contains pluripotent stem cells, named neoblasts, a term first used by Harriet Randolph to describe a particular cell type in the annelid Lumbriculus. Randolph reported that some species of earthworms contain large, undifferentiated, embryonic-like cells with a high nuclei-to-cytoplasm ratio, and she named them neoblasts (3). This word later adopted to describe similar cells in planarians. By morphology, neoblasts represent $\sim 25 \sim 30 \%$ of all pla- 
narian cells. The progeny of neoblasts have been shown to produce epidermis, rhabdite cells, muscle, and germ cells, among others. Considering that neoblasts are the only dividing cell type in planarians, they may well be totipotent stem cells (4). Neoblasts express about 4000 genes, including Genes important for pluripotency in ESCs, including regulators as well as targets of OCT4 (5). They also express transcripts for the PIWI proteins Smedwi-1 and Smedwi-2, the Bruno-like protein Bruli, and a Tudor protein. These proteins are typically found in association with nuage, an electron-dense perinuclear organelle present in germ cells, which plays a role in transposon silencing and maintenance of genome integrity (5), suggesting the existence of a common ancestral state of germ cells and neoblasts (6). Techniques for studying gene function in planarians, such as RNAi (7) and in situ hybridizations (8), combined with the characterization of a large number of cDNAs from the species Schmidtea mediterranea (9), and recent RNA sequencing approaches have allowed the initiation of molecular genetic studies of planarian biology (4). Given that $85 \%$ of the genes that yielded regeneration phenotypes in the $S$. mediterranea RNAi screen are conserved in other animals, the results of regeneration screening in planarians could serve as a good point of departure to determining the extent of conservation of regeneration mechanisms among the metazoans (10). Based on different expressing transcripts, neoblast populations are considering as three categories. Category 1 of neoblasts that posit in the most middle parts of the planarian mesenchyme are the only neoblasts capable of self-renewality. Using an asymmetrical division, category 1 of neoblasts generate category 2 , which they posit more peripherally to the category 1 of neoblasts. This category of neoblasts is not dividing, as it only can differentiate to category 3 of neoblasts, the most peripheral category of neoblasts in the planarian mesenchyme. In the next step, category 3 of neoblasts can differentiate to differentiated cells that lost during age or injury (11). Wagner and colleagues were able to show that if planaria were irradiated at a dosage such that nearly all neoblasts were destroyed, there would be some individuals in which a single neoblast survived and made a colony. From this neoblast, dividing progenitor cells formed, ultimately producing cell types of all germ layers and demonstrating the presence of pluripotent cells in the adult body. In addition to that, even a colonogenic neoblast, when transplanted from an asexual biotype to a lethally irradiated sexual biotype, can generate a colony and convert the sexual biotype in to an asexual biotype (12).

\section{Naïve versus primed model of neoblasts}

Historically two models for explaining neoblast specification in planarians were considered. In the 'naïve neoblast model', neoblasts produce non-dividing, multipotent blastema cells. Cells in the neoblast population are essentially all the same, responding like drones to wounds by simply migrating and dividing, producing the blastema cells. The action would then happen in blastema cells, with these multipotent and naïve postmitotic cells adopting appropriate identities based on the external signals that they receive; for example, as a consequence of their position in a blastema. In the 'specialized neoblast model', neoblasts involved in regeneration have different fates. These specialized neoblasts produce different lineage-committed and nondividing blastema cells (13).

Scimone and his coworker's propose that cNeoblasts (directly, or via their descendants) begin expressing numerous transcription factors of specific lineages in distinct neoblast cells. In this model, almost all of the lineages formed during development could be reconstituted during regeneration, with progenitors that generate and comprise planarian blastemas being a heterogeneous patchwork of lineage-specified cells. Neoblasts have largely been considered a homogeneous stem cell population. Most studies, however, analyzed neoblasts at the population rather than the single-cell level, leaving the degree of heterogeneity in this population unresolved (14). Using single cell approaches Wolfswinkel and his coworkers identified two prominent neoblast classes which they named zeta and sigma classes. Zeta-neoblasts encompass specified cells that give rise to an abundant postmitotic lineage, including epidermal cells, and are not required for regeneration. By contrast, sigma-neoblasts proliferate in response to injury, possess broad lineage capacity, and can give rise to zeta-neoblasts. Their findings indicated that planarian neoblasts comprise two major and functionally distinct cellular compartments. Model of the neoblast population is shown in Fig. 1 (6).

\section{Response to wounding in planarians}

Historically, planarian regeneration has been subdivided into two types of processes defined by the terms "epimorphosis" and "morphallaxis" (15). The stimulus for regeneration in planarians is injury. Amputation elicits a series of responses that ultimately result in a minimization of tissue loss. First, the animal pulls away from the wounding agent, possibly reflecting a predator avoidance reflex. A strong muscular contraction at the site of wounding occurs within seconds and minimizes the surface area of the 


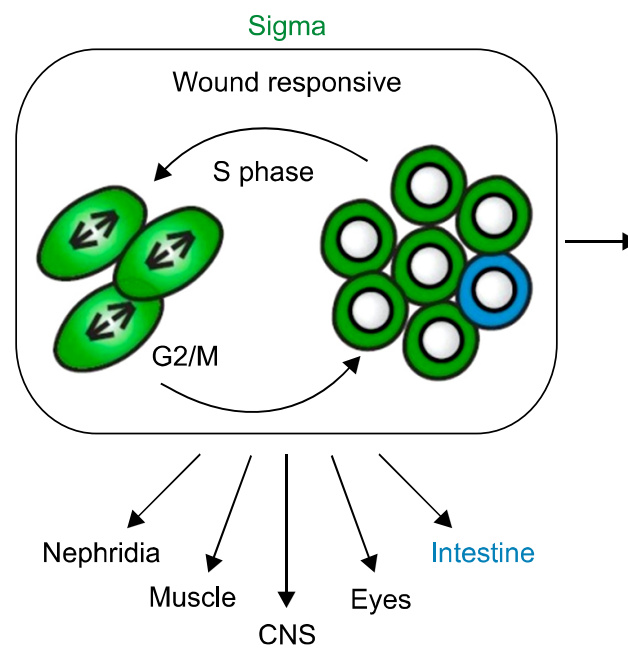

wound (16). Specialized planarian cells, referred to as rhabdites, release their contents at the wound site producing a protective mucosal covering, with possible immunological functions (17). A head fragment containing the brain will continue to locomote, possibly to escape the fate its body might have befallen to a hungry predator. Although trunk fragments can move and typically keep their ventral sides down, they remain relatively stationary during regeneration. A thin layer of epithelium covers the wound within $30 \mathrm{~min}$, a process that occurs by cell spreading rather than proliferation. The spreading involves both dorsal and ventral epithelial cells, which lose their characteristic morphologies as they cover the wound. In contrast to wounds produced in humans, scarring (i.e., deposition of dense collagenous fibers) does not seem to occur in planarians. As a result, the epithelium is in direct contact with tissues at the site of amputation. Because amputation and wound healing provide a context in which dorsal and ventral epidermis come into direct contact with each other, it has been suggested that this dorsal/ventral (D/V) interaction may trigger the regenerative response (4). Neoblasts can sense this heterogeneity in dorsoventral positional information and response to it by proliferation and migration to the amputation site. In the next step neoblast progenies can take participate in the structure of the regeneration blastema, an unpigmented epithelial/mesenchymal bud. During the following days the differentiated cells can generate from blastema differentiation and morphallaxis regeneration happens, during which the anatomical proportion of the animal is restored. In the last stage of planarian regeneration the behavioral characteristic of the differentiated cells restored (10). As with any stem cell, neoblast proliferation needs to be tightly regulated. Thus,
Fig. 1. Model of the neoblast population. Two major classes, the sigma-class and the zeta-class, represent functionally separate neoblast compartments. sNeoblastsare able to self-renew and collectively give rise to a wide range of tissue types. Over the course of $\mathrm{S}$ phase, a subset of the sNeoblasts gains markers specific for the zeta-class. These cells give rise to the prog-1-related lineages and to epidermal cells.

either blocking the capacity of neoblasts to proliferate or depleting their population leads to the loss of regenerative capacity. In contrast, an excess of neoblast proliferation can lead to the formation of overgrowths or tumors. Deciphering how this regulation is achieved is essential in order to understand not only the cellular basis of planarian regeneration but also the role of stem cells in processes such as tumorigenesis (18). It has been suggested, for instance, that animals with high regenerative capabilities (such as planarians) appear to be more refractory to the development of spontaneous or induced tumors (19). In spite of regeneration, injury induces immune response in planarians, in which a phagocytic, mesenchymal cell, named reticular cell is activated. Within $10 \mathrm{~h}$ of injury in the presence of bacteria, the reticular cell migrate in to the wound, phagocytosis and encapsulate bacteria. A recently identified group of molecules secreted by macrophages, maresins, enhance macrophage phagocytosis. When exposed to human maresin MaR1, the rate of planarian anterior tissue regeneration increased. These data indicate that key planarian signaling components can respond to human MaRl, and thus conservation exists between human and planarian maresins and their signal cascades (20).

\section{Polarity in planarians}

About a century ago Thomas haunt Morgan attempted to explain the extraordinary regenerative ability of planarians by positing two opposing morphogenetic gradients of formative head stuff and tail stuff along the anterior-posterior axis. When a planarian is amputated transversely, two fragments are generated and are capable of regenerating. The term polarity has been used to describe 
the fact that an anterior-facing wound will regenerate a head and a posterior-facing wound will regenerate a tail. Morgan suggested that something in the piece itself determines that a head shall develop at the anterior cut surface and a tail at the posterior cut surface. This "something" is what we call "polarity" (15). Recently it has been cleared that muscle cells and neurons express positional control genes (PCGs) and neoblasts can sense its positional information via these positional control cells (PCCs) around them (21).

Nowadays the identities of substances that make this polarity in the planarian body are clarified to some extent. The nervous system of planarians is composed of two hemispheres that form the conversed $U$ shaped brain of the animals. This conversed $U$ shaped brain, connects with two ventrally nerve cords that extend toward the most posterior tip of the animal (22). Within these nerve cells from the end of the $U$ shaped brain, Hedgehog (Hh) granules are composed and transformed to the posterior part of the body, using microtubules associated proteins. These gradients of $\mathrm{Hh}$ accumulated in the most posterior part of the body triggers the wingless signaling in the differentiated muscle cells around the neoblasts. Neoblasts can sense this posteriorzing gradient of wingless, which makes them have posterior identity. In the case of planarian amputation, Hh granules are always accumulated in the most posterior parts of the amputation surface, make these parts more potent for tail formation. Wnt $\beta$-catenin signaling also regulates tissue homeostasis and regeneration in metazoans (23).

In planarians, Wnt ligands are thought to control tissue polarity by shaping a $\beta$-catenin activity gradient along the anterior-posterior axis. A teashirt (tsh) ortholog is induced planarian and vertebrate regeneration in a $\beta$-catenin - dependent manner (24). On the other hand planarian wnt/ $\beta$-catenin signaling has been shown to act upstream to the LIM-homeobox genes at the posterior end (25). Like vertebrates, formation of anterior parts of the planarian body is due to FGF signaling (26). There are two FGF receptor families in planarians; FGFRL1 and FGFR3, and a FGF receptor related molecule named nou-darake (ndk), which is expressed in the head region. Ndk lacks the cytoplasmic kinase domains characteristic of the FGF receptor families and only restricts FGF signaling to the anterior parts of the body (27). The interaction of FGF and Wnt signaling within the planarian body, along the anterior-posterior body makes different parts of the body, including head, Pre-pharynx, pharynx and tail (28). Recently, it was proposed that subepidermal muscle cells are the cellular source of positional information by expressing posi- tion control genes (PCGs) such as genes encoding WNTs and their inhibitors (21). In addition to anterior-posterior axis, planarian body has polarity along its dorsal-ventral axis. Just as in vertebrate and flies, the dorsal- ventral axis of regenerating cells in planarians is regulated by BMP and its inhibitors (26), like ADMP (29) as well as noggin like genes (30).

\section{Conclusion}

Planarians are able to regenerate a complete animal, including the brain and reproductive system, after any kind of amputation. Although their striking regenerative capacity has attracted generations of biologists, recent years have seen them transformed into an essential model for the study of regeneration and stem cell biology using modern molecular and genomic tools. The impressive plasticity of planarians is based upon the presence in adult animals of a unique type of totipotent stem cells named neoblasts (4). Planarians represent an ideal system for molecular and cellular investigations because their gene function can readily be studied in adults via RNAi and in situ hybridizations (7). On the other hand a variety of genes and cell signaling molecules related to neoblast self-renewality and stemness are conserved in human $(5,10)$. Molecular genetic studies in planarians have revealed that orthologs of numerous embryonic patterning genes in other organisms have roles in adult planarian tissues for instructing tissue turnover and regeneration (31). Planarians also have an intrinsic immune system capable of resistance to bacterial infection. Recently a planarian ortholog of MORN2 has identified as a key component in LC3-associated phagocytosis and resistance to bacterial infection (32). A variety of characteristics make planarians an extraordinary model for regeneration studies; first, the animal is one of the simplest metazoans in which regeneration is patently manifested. Second, the organism is relatively easy to manipulate experimentally. Indeed, there exists more than 100 years of scientific literature reporting experimentation with planarians (4). Pronounced limitations of somatic tissue turnover and regenerative properties in current invertebrate models, coupled with the difficulty of studying vertebrate somatic stem cells in vivo, are compelling reasons to examine and test the suitability of planarians to inform both regeneration and stem cell biology (2). In This review we attempted to show some important aspects of planarian characteristics make this animal an extraordinary model for regenerative medicine researches. On the other hand a variety of genes and signaling molecules conserved between this animals and higher vertebrates as 
well as human makes this animal a good model for study about diseases as well as Parkinson (33) and may provide new ideas for handling mouse and human ES cells for therapeutic use in the near future (34).

\section{Potential conflict of interest}

The authors have no conflicting financial interest.

\section{References}

1. Elliott SA, Sánchez Alvarado A. The history and enduring contributions of planarians to the study of animal regeneration. Wiley Interdiscip Rev Dev Biol 2013;2:301-326

2. Sánchez Alvarado A. Planarian regeneration: its end is its beginning. Cell 2006;124:241-245

3. Randolph H. The regeneration of the tail in lumbriculus. J Morphol 1892;7:317-344

4. Reddien PW, Sánchez Alvarado A. Fundamentals of planarian regeneration. Annu Rev Cell Dev Biol 2004;20:725757

5. Onal P, Grün D, Adamidi C, Rybak A, Solana J, Mastrobuoni G, Wang Y, Rahn HP, Chen W, Kempa S, Ziebold U, Rajewsky N. Gene expression of pluripotency determinants is conserved between mammalian and planarian stem cells. EMBO J 2012;31:2755-2769

6. van Wolfswinkel JC, Wagner DE, Reddien PW. Single-cell analysis reveals functionally distinct classes within the planarian stem cell compartment. Cell Stem Cell 2014;15:326339

7. Sánchez Alvarado A, Newmark PA. The use of planarians to dissect the molecular basis of metazoan regeneration. Wound Repair Regen 1998;6:413-420

8. Umesono Y, Watanabe K, Agata K. A planarian orthopedia homolog is specifically expressed in the branch region of both the mature and regenerating brain. Dev Growth Differ 1997;39:723-727

9. Sánchez Alvarado A, Newmark PA, Robb SM, Juste R. The Schmidtea mediterranea database as a molecular resource for studying platyhelminthes, stem cells and regeneration. Development 2002;129:5659-5665

10. Sánchez Alvarado A, Tsonis PA. Bridging the regeneration gap: genetic insights from diverse animal models. Nat Rev Genet 2006;7:873-884

11. Eisenhoffer GT, Kang H, Sánchez Alvarado A. Molecular analysis of stem cells and their descendants during cell turnover and regeneration in the planarian Schmidtea mediterranea. Cell Stem Cell 2008;3:327-339

12. Wagner DE, Wang IE, Reddien PW. Clonogenic neoblasts are pluripotent adult stem cells that underlie planarian regeneration. Science 2011;332:811-816

13. Reddien PW. Specialized progenitors and regeneration. Development 2013;140:951-957

14. Scimone ML, Kravarik KM, Lapan SW, Reddien PW. Neoblast specialization in regeneration of the planarian Schmidtea mediterranea. Stem Cell Reports 2014;3:339-352
15. Morgan TH. Regeneration. New York: The Macmillan Company; 1901. 316

16. Newmark PA, Sánchez Alvarado A. Not your father's planarian: a classic model enters the era of functional genomics. Nat Rev Genet 2002;3:210-219

17. Reisinger E, Kelbetz S. Fine structure and discharge mechanism of rhabdites. Z Wiss Mikrosk 1964;65:472-508

18. Almuedo-Castillo M, Sureda-Gómez M, Adell T. Wnt signaling in planarians: new answers to old questions. Int J Dev Biol 2012;56:53-65

19. Oviedo NJ, Beane WS. Regeneration: The origin of cancer or a possible cure? Semin Cell Dev Biol 2009;20:557-564

20. Lee SM, Kok KH, Jaume M, Cheung TK, Yip TF, Lai JC, Guan Y, Webster RG, Jin DY, Peiris JS. Toll-like receptor 10 is involved in induction of innate immune responses to influenza virus infection. Proc Natl Acad Sci U S A 2014;111:3793-3798

21. Witchley JN, Mayer M, Wagner DE, Owen JH, Reddien PW. Muscle cells provide instructions for planarian regeneration. Cell Rep 2013;4:633-641

22. Umesono Y, Tasaki J, Nishimura Y, Hrouda M, Kawaguchi E, Yazawa S, Nishimura O, Hosoda K, Inoue T, Agata K. The molecular logic for planarian regeneration along the anterior-posterior axis. Nature 2013;500:73-76

23. Yazawa S, Umesono Y, Hayashi T, Tarui H, Agata K. Planarian Hedgehog/Patched establishes anterior-posterior polarity by regulating Wnt signaling. Proc Natl Acad Sci U S A 2009;106:22329-22334

24. Reuter H, März M, Vogg MC, Eccles D, Grífol-Boldú L, Wehner D, Owlarn S, Adell T, Weidinger G, Bartscherer K. $B$-catenin-dependent control of positional information along the AP body axis in planarians involves a teashirt family member. Cell Rep 2015;10:253-265

25. Hayashi T, Motoishi M, Yazawa S, Itomi K, Tanegashima C, Nishimura O, Agata K, Tarui H. A LIM-homeobox gene is required for differentiation of Wnt-expressing cells at the posterior end of the planarian body. Development 2011;138: 3679-3688

26. Gilbert SF. Developmental biology. 10th ed. Sunderland, Mass, USA: Sinauer Associates Inc; 2013.

27. Cebrià F, Kobayashi $\mathrm{C}$, Umesono $\mathrm{Y}$, Nakazawa $\mathrm{M}$, Mineta K, Ikeo K, Gojobori T, Itoh M, Taira M, Sánchez Alvarado A, Agata K. FGFR-related gene nou-darake restricts brain tissues to the head region of planarians. Nature 2002;419: 620-624

28. Tasaki J, Shibata N, Nishimura O, Itomi K, Tabata Y, Son F, Suzuki N, Araki R, Abe M, Agata K, Umesono Y. ERK signaling controls blastema cell differentiation during planarian regeneration. Development 2011;138:2417-2427

29. Gaviño MA, Reddien PW. A Bmp/Admp regulatory circuit controls maintenance and regeneration of dorsal-ventral polarity in planarians. Curr Biol 2011;21:294-299

30. Molina MD, Neto A, Maeso I, Gómez-Skarmeta JL, Saló E, Cebrià F. Noggin and noggin-like genes control dorsoventral axis regeneration in planarians. Curr Biol 2011;21: 300-305 
31. Reddien PW. Constitutive gene expression and the specification of tissue identity in adult planarian biology. Trends Genet 2011;27:277-285

32. Abnave P, Mottola G, Gimenez G, Boucherit N, Trouplin V, Torre C, Conti F, Ben Amara A, Lepolard C, Djian B, Hamaoui D, Mettouchi A, Kumar A, Pagnotta S, Bonatti S, Lepidi H, Salvetti A, Abi-Rached L, Lemichez E, Mege JL, Ghigo E. Screening in planarians identifies MORN2 as a key component in LC3-associated phagocytosis and re- sistance to bacterial infection. Cell Host Microbe 2014;16: 338-350

33. Prokai D, Nguyen T, Kamrowski K, Chandra A, Talamantes T, Baxter LR, Prokai L. An exploratory evaluation of tyrosine hydroxylase inhibition in planaria as a model for parkinsonism. Int J Mol Sci 2013;14:23289-23296

34. Agata K, Tasaki J, Nakajima E, Umesono Y. Recent identification of an ERK signal gradient governing planarian regeneration. Zoology (Jena) 2014;117:161-162 